\title{
Motivated ignorance, rationality, and democratic politics
}

\author{
Daniel Williams ${ }^{1,2}$ (D)
}

Received: 17 February 2019 / Accepted: 20 January 2020 / Published online: 4 February 2020

(c) The Author(s) 2020

\begin{abstract}
When the costs of acquiring knowledge outweigh the benefits of possessing it, ignorance is rational. In this paper I clarify and explore a related but more neglected phenomenon: cases in which ignorance is motivated by the anticipated costs of possessing knowledge, not acquiring it. The paper has four aims. First, I describe the psychological and social factors underlying this phenomenon of motivated ignorance. Second, I describe those conditions in which it is instrumentally rational. Third, I draw on evidence from the social sciences to argue that this phenomenon of rational motivated ignorance plays an important but often unappreciated role in one of the most socially harmful forms of ignorance today: voter ignorance of societal risks such as climate change. Finally, I consider how to address the high social costs associated with rational motivated ignorance.
\end{abstract}

Keywords Ignorance $\cdot$ Motivated ignorance $\cdot$ Rational ignorance $\cdot$ Democracy . Motivated cognition · Voter ignorance

We know some men will not read a letter which is supposed to bring ill news; and many men forbear to cast up their accounts, or so much as think upon their estates, who have reason to fear their affairs are in no very good posture. How men... can satisfy themselves with a lazy ignorance, I cannot tell: but methinks they have a low opinion of their souls... (Locke [1689] 1976, p. 576).

Genuine ignorance can be an advantage to a player if it is recognized and taken into account by an opponent (Schelling 1960, p. 161).

Daniel Williams

dw473@cam.ac.uk

1 Corpus Christi College, University of Cambridge, Cambridge, United Kingdom

2 Centre for Philosophical Psychology, University of Antwerp, Lange Sint-Annastraat 7, S.208, 2000 Antwerp, Belgium 


\section{Introduction}

"All men, by nature, desire to know," declares the opening line of Aristotle's Metaphysics (Ross 1924, p. 255). Without qualification, of course, the statement is absurd. The set of possible knowledge is infinite. We must be selective. Very often, for example, the costs of acquiring knowledge outweigh the benefits of possessing it. This phenomenon of rational ignorance embodies a simple idea that has nevertheless had a large impact in the social sciences (Somin 2015). For example, Downs (1957) famously appealed to rational ignorance to explain the shocking levels of ignorance among voters in contemporary democracies. Because an individual's vote has a negligible impact on political decision-making, the costs of becoming informed massively outweigh the benefits of being informed. The upshot, argued Downs, is that most voters remain radically_and rationally-ignorant about matters of fact that would seem to be highly relevant to the issues that they vote on.

In this paper I focus on a related phenomenon that has received less attention in philosophy and the social sciences: cases in which an individual remains ignorant because of the anticipated costs of possessing knowledge, not acquiring it. Consider a puzzling example: many individuals who are at risk for Huntington's disease and HIV refuse to take free, accurate and anonymous tests (Oster et al. 2013). As a result, they remain ignorant of knowledge that they could easily possess-knowledge, in fact, that would seem to be of immense practical value. This phenomenon-I will call it "motivated ignorance"-generates a variety of questions that have received insufficient attention in philosophy and the psychological and social sciences. ${ }^{1}$ What does it involve? Under what conditions, if any, is it rational? How widespread is it? I have two primary aims in this paper: first, to develop an account of motivated ignorance that addresses such questions; second, to argue that a rational form of motivated ignorance plays an important but often unappreciated role in the high levels of voter ignorance in contemporary democracies. That is, a substantial component of this ignorance is a response to the costs of being informed, not becoming informed. ${ }^{2}$

I structure the paper as follows. In Sect. 2 I introduce motivated ignorance and I describe the psychological and social factors that underlie it. In Sect. 3 I outline those conditions in which motivated ignorance is instrumentally rational, and I consider how it relates to self-deception. In Sect. 4 I draw on evidence from the social sciences to argue that rational motivated ignorance plays an important role in one of the most socially harmful forms of ignorance today: voter ignorance of societal risks

\footnotetext{
${ }^{1}$ Important exceptions in philosophy include critical philosophers of race (e.g. Mills 2007) and feminist philosophers (e.g. Frye 1983) who have focused on the way in which members of elite demographic groups benefit from socio-political structures that uphold ignorance (see Woomer 2019), as well as recent philosophical work on 'willful' ignorance (Lynch 2016; Wieland 2016a) and 'strategic' ignorance (Wieland 2016b). Important exceptions in psychology and behavioural economics include Golman et al. (2015), Hertwig and Engel (2016) and Sweeny et al. (2010). Thagard (2013) uses the term "motivated ignorance".

${ }^{2}$ I use "being informed" and "becoming informed" as synonyms for "possessing knowledge" and "acquiring knowledge," respectively, throughout.
} 
such as climate change. Finally, I conclude in Sect. 5 by exploring how to combat the practical incentives that place knowledge and rational self-interest in conflict.

\section{Motivated ignorance}

What is motivated ignorance? Popular culture is replete with expressions that describe or allude to it: "denial," "burying your head in the sand," "ignorance is bliss," "what you don't know can't hurt you," "turning a blind eye," and so on. This suggests a widespread familiarity with the phenomenon. In this section I seek to clarify what this phenomenon involves, and I identify important subcategories of it.

As noted above, motivated ignorance should first be distinguished from what I will call "acquisitional ignorance," the act of maintaining one's ignorance because the anticipated costs of becoming informed outweigh the anticipated benefits of being informed. Acquisitional ignorance is a simple consequence of the fact that we are finite creatures with limited time, energy and resources. Acquiring knowledge therefore has costs-both opportunity costs and the various costs involved in the process of acquisition. When an individual avoids some particular body of knowledge in response to such acquisitional costs, she exhibits acquisitional ignorance. In much of social science, it is assumed that the benefits of knowledge are purely instrumental, such that new information is only valuable to the extent that it improves our decisions (Stigler 1961). Much of our concern with knowledge does not have this character, however. For example, we often learn about things simply because we find them intrinsically interesting. Nevertheless, the benefits of potential knowledge - instrumental or otherwise - are almost always dwarfed by the costs of acquisition. Even Aristotle was selective about the knowledge he sought to acquire.

Motivated ignorance involves a form of ignorance that is driven not by the costs of acquiring knowledge but by an active aversion to possessing it. Golman et al. (2017, p. 97) call this active information avoidance and they argue that for ignorance to be "active" in this way it must satisfy two conditions: "(1) the individual is aware that the information is available, and (2) the individual has free access to the information or would avoid the information even if access were free." The first condition flags something important that plausibly applies to acquisitional ignorance as well: ignorance is only ever a choice in cases in which the individual is aware that potential knowledge exists. When one lacks this awareness, one's ignorance is neither acquisitional nor motivated but merely "inadvertent" (Somin 2015). The second condition, however, is used to distinguish acquisitional ignorance from active information avoidance: individuals exhibiting active information avoidance would still remain ignorant even if the acquisitional costs pertaining to a body of knowledge were eliminated.

How should active information avoidance be understood? In using the term "motivated ignorance," I am drawing a deliberate connection between this phenomenon and what is often called "motivated reasoning" in contemporary psychology. Motivated reasoning is the well-established "tendency to conform information processing to some goal collateral to accuracy" (Kahan 2017a, p. 1). Motivated reasoners thus deploy their reasoning abilities "to arrive at conclusions that they want to 
arrive at," rather than those conclusions that are most likely to be true in light of the evidence available to them (Kunda 1990, p. 480). With some important qualifications (see below), motivated ignorance can be understood as one manifestation of this tendency. Whereas motivated reasoning is typically understood to involve a "motivation to arrive at particular conclusions" (Kunda 1990, p. 480), however, motivated ignorance involves the opposite motivation: to avoid certain conclusions. Nevertheless, there is an obvious symbiosis between these phenomena: insofar as one is motivated to arrive at conclusions for reasons independent of their truth, one will likewise be motivated to avoid acknowledging the truth of propositions in tension with such conclusions. Motivated reasoning thus inevitably gives rise to motivated ignorance.

There are several important clarifications and caveats that must be attached to this simple story, however. First, motivated ignorance need not involve the motivation to avoid "particular conclusions," at least if this is taken to involve knowledge of the specific content of those conclusions (Kunda 1990, p. 480). In many cases of motivated ignorance, the individual is unaware of the specific content of the information that she seeks to avoid. For example, if I avoid opening a letter because I fear that it brings bad news, I am likely ignorant of its specific contents. The relevant motivation is thus plausibly to avoid beliefs that generate psychologically unpleasant or distressing states, which combines in this case with my expectation that reading the letter is likely to give rise to beliefs with this aversive character.

Second, it is plausibly an essential component of motivated reasoning as it is described in the psychological literature that one is consciously unaware of the role that one's motives play in biasing one's cognitive processes. That is, motivated reasoning is accompanied by a powerful illusion of impartiality, such that "people do not realize that the [reasoning] process is biased by their goals" (Kunda 1990, p. 486). Although many examples of motivated ignorance share this character-for example, an individual in denial is typically not aware that she is in denial-many others do not. I might be very much aware of the fact that I am not opening a letter because I fear that it brings bad news. My motivation and its effects are thus transparent to me. Nevertheless, I am still exhibiting motivated ignorance. I return in more depth to this important issue of the role of self-knowledge in motivated ignorance in Sect. 3.

Third, it is common within philosophy to distinguish between intentional agency and merely motivated behaviour (Mele 2001), and motivated reasoning is often understood to be restricted to the latter. Crucially, motivated ignorance as I will understand it is consistent with - although does not require-maximal agency and all that this entails, including intentions, effort, control, deliberation and so on (see Funkhouser 2019, pp. 120-121).

Finally, motivated ignorance need not be restricted to cases in which one's motivations influence the process of explicit reasoning. In many cases, for example, the agent's motive-perhaps in combination with an intention and conscious deliberation-simply drives her to avoid certain information altogether, as with someone who avoids taking a medical test because she is afraid of discovering the results. More generally, motivated ignorance can be sustained by a complex panoply of cognitive and behavioural processes, from simple forms of physical avoidance to biased 
belief updating, selective recall, rationalisation and more. Woomer (2019, p. 73) helpfully characterises "the kind of non-knowing at the heart of ignorance that is cultivated or maintained by individual agents" as a form of agential insensitivity, which manifests "as a failure to either attend to relevant and available evidence, or appropriately interpret evidence that is attended to." 3 What matters in classifying a state of ignorance as motivated is that the individual's motives are causally responsible for this state of agential insensitivity. How such motives exert this causal influence is a separate question, and often an extremely complicated one.

To summarise, then, motivated ignorance involves any motivated process that enables an individual to avoid acquiring some specific body of knowledge, where this motivation has nothing to do with the costs of acquiring that knowledge. Of course, this is a maximally general description. I will now show how this phenomenon can be decomposed into different subcategories.

\subsection{Forms of motivated ignorance}

There are many ways in which one can taxonomize different forms of motivated ignorance. ${ }^{4}$ One crucial distinction that must be made in any such taxonomy, however, is between what I will call personally motivated ignorance and socially motivated ignorance, even if-as I argue below-both phenomena often co-exist in single cases.

Personally motivated ignorance involves cases in which the agent is motivated to remain ignorant for reasons independent of the effects of this ignorance on other agents. Two examples of this phenomenon are especially important (see Sweeny et al. 2010). First, one can be motivated to avoid knowledge in the service of emotional regulation. Knowledge often leads to distressing or aversive emotional states such as shame, regret, jealousy, embarrassment and so on. One way to avoid such negative emotional experiences is thus to avoid acquiring information that might lead to them. Second, one can be motivated to avoid knowledge that leads to undesirable actions. For example, consider an individual in denial about her spouse's infidelity because recognising this infidelity would "force" her, given her other beliefs and desires, to leave the relationship_an outcome that she desperately wants to avoid. The generic motive to avoid certain actions can thus motivate avoidance of any knowledge that might lead one to undertake them.

Socially motivated ignorance involves cases in which the agent is motivated to remain ignorant because of the anticipated effects of this ignorance on other agents. At least one example of this form of motivated ignorance has been extensively studied in game theory and it forms the basis of the second epigraph to this paper: Schelling' (1960, p. 161) remark that "ignorance can be an advantage to a player if it is recognized and taken into account by an opponent." In such cases the motivation

\footnotetext{
${ }^{3}$ Woomer (2019) also explicitly links this phenomenon of agential insensitivity to work on motivated reasoning in psychology.

${ }^{4}$ See Golman et al. (2015), Hertwig and Engel (2016) and Sweeny et al. (2010) for different ways of taxonomizing a similar phenomenon.
} 
to remain ignorant is driven by the motivation to persuade other agents of one's ignorance, which is the real goal. Perhaps the most obvious real-world examples of socially motivated ignorance are cases in which individuals attempt to avoid social or legal accountability by avoiding the knowledge that would bestow such accountability on them. As Simon (2004, p. 2) puts it, "Because both law and social opinion hesitate to condemn...ignorant conduct, actors are tempted to affect... deliberate ignorance in order to diminish accountability." Those involved in the Watergate scandal, for example, revealed "intense faith in the immunizing power of deliberate ignorance" (Simon 2004, p. 5).

As I mentioned above, paradigmatic examples of motivated reasoning involve cases in which the individual harbours a desire to arrive at certain conclusionsto form certain beliefs. In the vocabulary of rational choice theory, agents have preferences over beliefs, leading them to seek out and process information in ways designed to satisfy such belief-based preferences (Bénabou and Tirole 2016). ${ }^{5}$ Such "cherished beliefs" inevitably give rise to a form of motivated ignorance: the motivation to remain ignorant of the truth of propositions in tension with them (Sweeny et al. 2010). Should this form of motivated ignorance be understood as personally or socially motivated ignorance?

The answer to this question depends on why the relevant agent cherishes the belief. If one values a belief for reasons independent of its effects on other agents, the motivated ignorance that results will be an example of personally motivated ignorance. Motivated reasoning often has this purely personal character. In wishful thinking, for example, one desires to believe that $p$ because one desires that $p$. If such beliefs motivate one to avoid or distort information that challenges them, one's ignorance will be a case of personally motivated ignorance. In some cases, however, agents are motivated to hold beliefs because other agents respond to such beliefs in a desirable way. That is, such beliefs are "cherished" because they are socially rewarded (Kurzban 2012; von Hippel and Trivers 2011; Williams 2018). For example, certain beliefs function as badges of group membership, enabling us to signal our membership of and loyalty to desirable coalitions - a phenomenon that I return to in Sect. $4 .^{6}$ If such socially adaptive beliefs (Williams 2019) motivate one to avoid or distort information in tension with them, one's ignorance will be a case of socially motivated ignorance.

Although this distinction between personally and socially motivated ignorance is conceptually clear, it is often difficult to distinguish or disentangle them in realworld contexts. Consider an infamous example: many bystanders throughout the Holocaust sought to remain ignorant of the atrocities being committed in their communities (Bankier 1996). Was this motivated ignorance socially strategic - a way of avoiding potential accountability to enemy forces who might discover such crimesor a way of protecting their own consciences, or both? We will likely never know.

\footnotetext{
5 Here I assume that the preferences concern beliefs, and not the states of affairs those beliefs represent, in line with so-called "mind-directed" theories of self-deception (see Funkhouser 2019, pp. 59-64; Nelkin 2002) (see Sect. 3.1 for a discussion of self-deception).

6 See Funkhouser (2017) on beliefs as signals.
} 
In general, it is often difficult to tease apart different motivations for ignorance, not least because multiple motives can and often do co-exist and complement each other in individual cases.

\section{Rational motivated ignorance}

Is motivated ignorance rational? Importantly, my interest here is in whether it is instrumentally rational-that is, whether it enables individuals to successfully achieve their own ends. Motivated ignorance is of course often epistemically irrational, insofar as it involves forms of information sampling and processing that obstruct the production of knowledge. ${ }^{78}$ Further, it can also plausibly be unethical if the relevant individual's motivated ignorance inflicts costs on others, although I will not consider complex ethical and philosophical questions surrounding individual responsibility for motivated ignorance in this paper.

Intuitions about the instrumental rationality of motivated ignorance pull in opposite directions. Consider the character in Douglas Adams's 'The Restaurant at the End of the Universe' who wears a pair of "Peril Sensitive Sunglasses": "At the first hint of trouble, they turn totally black and thus prevent you from seeing anything that might alarm you" (Adams 1980, p. 27). The joke, of course, is that ignoring present dangers is not a sensible way of avoiding them. In fact, it exacerbates the problem, rendering the individual more vulnerable to potential harm. This can seem like a good metaphor for understanding motivated ignorance - a form of willful blindness that at best brings temporary relief, but can lead to devastating consequences.

On the other hand, many examples of motivated ignorance seem like manifestations of rational self-interest. For example, perhaps the most influential case study of motivated ignorance within contemporary philosophy involves situations in which members of elite or dominant demographic groups wilfully avoid facts about the lives of oppressed or marginal groups and the nature of society more generally (Frye 1983; Mills 2007; Woomer 2019). This ignorance is widely thought to be strategically self-serving, enabling members of such privileged groups to preserve psychologically comforting illusions and avoid accountability. Insofar as the putatively ignorant members of such groups value these self-interested outcomes over ethical ones, their ignorance is plausibly instrumentally rational.

Is there a way to move beyond intuitions and identify the specific conditions that a case of motivated ignorance must satisfy to qualify as instrumentally rational?

\footnotetext{
7 An anonymous reviewer points out that it is controversial within epistemology that behaviour can be both epistemically irrational and yet instrumentally rational. Nevertheless, I assume along with mainstream psychology (e.g. Stanovich 2011) and much of philosophy (e.g. Bortolotti 2014) both a sharp conceptual distinction between the two forms of rationality and the possibility of information processing that is systematically biased away from truth (and thus epistemically irrational) and yet conducive to an individual's goals and interests (and so instrumentally rational).

${ }^{8}$ It may be that the mere avoidance of information is not sufficient for epistemic irrationality, such that not all examples of motivated ignorance are epistemically irrational. I thank an anonymous reviewer for pointing this out.
} 
To approach this question, it is first useful to focus on the simpler case of acquisitional ignorance. Acquisitional ignorance has been a central focus in the economics of information since the seminal work of Stigler (1961). By assuming the truth of certain axioms of rational choice, however, this work typically simply assumes that acquisitional ignorance is rational. Specifically, it assumes that acquisitional ignorance is driven by a form of expected utility maximization in which agents acquire information only up to the point where its expected marginal benefits are identical with its expected marginal costs. Nevertheless, one might use this framework not as a description of all actual decision-making but as the normative benchmark against which to evaluate the rationality of any given case of acquisitional ignorance: does the agent's decision to remain ignorant maximize expected utility?

Of course, people do not engage in the complex calculations relevant to expected utility maximization when they decide to avoid acquiring knowledge. Indeed, to do so in almost all circumstances would itself be irrational given the time and energy it would take (Somin 2015). Instead, most of the judgements and decisions that guide acquisitional ignorance are "intuitive": like almost all judgements and decisions that we make, they arise not from any process of conscious rational deliberation but from a complex array of heuristics, habits, emotions and other automatic processes (Kahneman 2003). Nevertheless, one might still ask to what extent our decisionmaking in such cases approximates expected utility maximization. In essence, this just boils down to the following question: is the agent's choice to remain ignorant sufficiently responsive to her interests - to the actual costs and benefits involved? Rational acquisitional ignorance does not require infallibility. As Somin (2015, p. 275) puts it, "Even the most rational individual might choose not to seek out information that in retrospect turns out to have been worth the cost of acquiring." To qualify as rational, however, it must be the case that the agent forms her judgement concerning the relative costs and benefits in a way that is sensitive to the range of relevant evidence at her disposal. In other words, whether acquisitional ignorance is instrumentally rational depends on whether the relevant agent came to judge the costs and benefits involved-even if only implicitly-in a way that was epistemically rational.

One might think that this intuitive framework will carry over straightforwardly to the case of motivated ignorance. Of course, acquisitional ignorance concerns the costs of acquiring knowledge whereas motivated ignorance concerns the costs of possessing it, but a similar lesson would seem to apply: an act of motivated ignorance is rational if and only if the agent's decision to remain ignorant is sufficiently responsive to her evidence concerning the costs and benefits of possessing the relevant body of knowledge. Again, such decisions are rarely underpinned by a conscious process of cost/benefit analysis, but one can still ask to what extent they are responsive to the agent's interests as manifest in the evidence at her disposal.

Nevertheless, motivated ignorance introduces a complication not found in acquisitional ignorance: in many cases of motivated ignorance, the subject is consciously oblivious to her motivation to remain ignorant. Indeed, many of those engaging in motivated ignorance will adamantly reject attempts to explain their epistemic position in terms of motivated ignorance. Paradigmatic cases of denial provide a clear example. An individual in denial about the destructive consequences of her drug 
use is not typically aware that she is in denial (Pickard 2016). In this way denial typically exhibits a kind of second-order motivated ignorance: in addition to the initial motivation to remain ignorant of a body of knowledge, it plausibly involves a second-order motivation to remain ignorant of that initial motivation.

Not all examples of motivated ignorance exhibit this lack of self-knowledge. Consider a labour union leader who deliberately avoids polling workers about their willingness to accept an offer from management, thus giving the impression of uncertainty about the strength of worker grievances and thereby improving her bargaining position (Golman et al. 2017, p. 105). This is a calculated form of socially motivated ignorance in which the relevant agent is consciously aware of her motive. An individual in denial about her spouse's infidelity is in a very different situation: although her state of ignorance is sustained by her motives, she is-at least in paradigm cases - consciously unaware of this fact. It is these examples of what I will call unconscious motivated ignorance that are difficult to understand as instrumentally rational: how can an agent's choice to remain ignorant be sensitive to her interests if she is consciously unaware of making that choice? It is one thing to choose to wear a pair of peril sensitive sunglasses. It is quite another to put them on without noticing.

This conclusion would be misguided, however. Of course, many examples of unconscious motivated ignorance are instrumentally irrational. Indeed, Alcoholics Anonymous describes the form of denial that often accompanies alcoholism as literal "insanity" (Alcoholics Anonymous 2001, p. 37; quoted in Pickard 2016, p. 278). Further, it is plausible that the lack of self-knowledge partially explains this instrumental irrationality in certain cases. Conscious deliberation over a decision enables one to integrate more information in a more flexible way than is possible for unconscious decision-making (Carruthers 2015), so the fact that unconscious motivated ignorance does not allow for such deliberation might generate important constraints that are absent in conscious forms of motivated ignorance.

Nevertheless, it is implausible that the possibility of conscious deliberation is necessary for instrumental rationality given how much of decision making occurs in the absence of such deliberation. It is widely held in contemporary psychology that unconscious motivated psychological processes can be highly sensitive to an individual's objective interests (Kurzban 2012; Von Hippel and Trivers 2011). Indeed, rendering certain motivations and the processes that they give rise to unconscious is itself plausibly strategic in many cases, preserving the conscious subject's sense of impartiality and thus facilitating plausible deniability (Simler and Hanson 2017). That is, if ignorance can be beneficial in general, then presumably ignorance of one's motives to be ignorant can also be beneficial. The rationality of unconscious motivated ignorance should thus not be ruled out a priori. The question is whether any given case of unconscious motivated ignorance is driven by psychological processes that are responsive to the relevant agent's interests. ${ }^{9}$ I will argue in Sect. 4

\footnotetext{
9 An anonymous reviewer helpfully points out that one must distinguish between short-term and longterm interests here, and argues that "the (instrumental) rationality of motivated ignorance is mostly shortterm, based on the fact that no misinformation and disinformation can be helpful in the long run either for the agent or for third parties." Although I agree that motivated ignorance is often short-sighted, I reject the assumption that is always so. The incentives pertaining to motivated ignorance discussed in Sect. 4, for example, are not changed by broadening the time horizon.
} 
that certain examples of unconscious motivated ignorance in the political domain satisfy this condition. First, however, I consider a potential objection to the foregoing analysis.

\subsection{Motivated ignorance and self-deception}

I have not mentioned a concept that many will think is highly relevant to the foregoing discussion: self-deception. This is purposeful. Despite an enormous body of philosophical work on self-deception, disagreement and controversy persist concerning every aspect of it, including what its defining characteristics are, what constitute paradigmatic examples of it, whether it exists-indeed, whether it even could exist-and which psychological states and processes it involves (see Funkhouser 2019 for an excellent review). By avoiding the term "self-deception," I have tried to identify general structural characteristics of motivated ignorance whilst steering clear of such controversies. Of course, this is not to say that there are no interesting questions concerning how the complex philosophical terrain surrounding selfdeception maps onto the phenomenon of motivated ignorance as I have described it, but I hope to postpone many of these questions to future work.

Nevertheless, there is one important issue here that cannot be postponed. Some philosophers have sought to draw a distinction between what they call "willful ignorance" (or "willful blindness") and self-deception (Holton 2001; Funkhouser 2019; Lynch 2016). For example, Holton (2001) argues that willful ignorance is consistent with knowledge of one's motivation to be ignorant, whereas self-deception is not. Funkhouser (2019, p. 70) argues that willful ignorance involves "an absence of information altogether rather than the presence of unwanted information," which he takes to be characteristic of self-deception. And Lynch (2016, p. 522) agrees with both such differences and suggests a range of additional ones, including the presence of fundamentally different doxastic states, different relations to evidence, and different levels of culpability, leading him to conclude that willful ignorance and selfdeception comprise "distinct psychological kinds."

Superficially, at least, what such authors call "willful ignorance" and "self-deception" seem to map onto conscious and unconscious motivated ignorance as I have described them. Thus, one might object that my treatment of motivated ignorance assimilates psychological phenomena that should in fact be kept apart for theoretical purposes.

Before addressing this worry, it is worth first explaining how the concepts of conscious and unconscious motivated ignorance map onto self-deception, at least as it is typically understood. Most obviously, conscious motivated ignorance does notor at least need not-involve anything resembling self-deception. A union leader who intentionally avoids polling workers in order to improve her bargaining position need not be self-deceived. By contrast, some examples of unconscious motivated ignorance do seem to qualify as self-deception. An individual in denial about her drug problem is a clear example. More generally, self-deception plausibly either just is unconscious motivated ignorance, insofar as it is driven by the motivation to avoid a body of knowledge, or it inevitably gives rise to unconscious motivated 
ignorance, insofar as it is driven by a motivation to protect a cherished belief. Nevertheless, unconscious motivated ignorance need not involve various additional ingredients that some theorists have thought to be essential to self-deception, including intentions (in addition to mere motives) and double book-keeping (i.e. holding two contradictory beliefs at the same time) (see Funkhouser 2019). Thus, on certain accounts of self-deception, unconscious motivated ignorance is a broader category than self-deception.

What about willful ignorance? Insofar as the defining characteristic of willful ignorance is the presence of self-knowledge, it maps on straightforwardly to conscious motivated ignorance as I have described it. As noted above, however, Lynch (2016) and others posit several other defining characteristics. Although such characteristics might be collectively definitional of an interesting phenomenon in its own right, they are not necessary for something to qualify as conscious motivated ignorance. To give only three examples:

First, Lynch (2016, pp. 511-512) argues that willful ignorance essentially involves ignorance of knowledge that one should possess. This normative dimension is irrelevant to whether something qualifies as conscious motivated ignorance. One is under no obligation to learn the ending of a film or novel, for example, but one can still be consciously motivated to avoid "spoilers." Indeed, one can be consciously motivated to remain ignorant of knowledge that one should not possess, such as intimate details that violate another's privacy or effective techniques of criminality (Fricker 2016, p. 144).

Second, Lynch (2016, p. 509) argues that willful ignorance cannot involve actively believing contrary to what one remains wilfully ignorant of. This phenomenon seems central to many cases of conscious motivated ignorance, however. For example, I might avoid taking a medical test precisely to protect my cherished belief that I am healthy. Lynch (2016, p. 509) rules this out in the case of willful ignorance for the following reason: "Calling... ignorance 'willful' implies that he chose to be ignorant by avoiding finding out whether $p$. But... [he] wouldn't count as having avoided finding out whether $p$ if he felt confident that not- $p$ already." It is difficult to see the force of this consideration, however. There is nothing that is obviously incoherent or even implausible in both believing that not- $p$ and yet actively avoiding evidence that $p$. Indeed, by Lynch's (2016) own admission, this sort of tension seems to be central to many cases of self-deception.

Third, Lynch (2016, p. 522) argues that willful ignorance can never involve encountering evidence that the proposition that one is ignorant of is true, only that it may be true. Once again, however, it is difficult to understand this claim in the case of conscious motivated ignorance. An infinite number of things may be true. It is unclear how evidence pertaining to a mere possibility like this could drive motivated ignorance of any kind. Further, many examples of conscious motivated ignorance appear to involve much stronger evidence. An individual might consciously avoid taking a medical test despite displaying symptoms of the relevant illness, for example.

Thus, many of the allegedly defining characteristics of willful ignorance as Lynch (2016) understands it do not seem to be essential to conscious motivated ignorance. Further, I think it is plausible that the differences in self-knowledge that distinguish 
conscious and unconscious motivated ignorance as I have characterised them are best thought of as differences of degree. That is, individuals can plausibly be more or less aware of their motivation to be ignorant, such that differences in self-knowledge exist along a continuum. Somebody who avoids taking a medical test might only dimly appreciate her motivation to be ignorant, and acknowledging that one is in denial is probably best thought of as a process where success and failure do not have sharply demarcated boundaries.

Finally, it is important to reiterate the point made above (Sect. 2.1): motivated ignorance can be sustained by a complex panoply of cognitive and behavioural strategies. Crucially, it is not my intention here to argue that all such strategies comprise a single psychological kind. There can be theoretical reasons for assimilating phenomena that do not involve a concern with psychological taxonomy. My aim here has been to draw attention to what unifies conscious and unconscious motivated ignorance from an epistemological point of view: namely, the motivation to remain ignorant of a body of knowledge for reasons independent of the costs of acquiring that knowledge. A fine-grained psychological investigation and taxonomy of the myriad ways in which such motivations exert their causal influence in different cases falls beyond the scope of the current paper.

\subsection{Summary}

To summarise, whether a given case of motivated ignorance is instrumentally rational depends on whether it is sufficiently responsive to the agent's interests as manifest in the evidence that she has at her disposal. This applies to both conscious motivated ignorance and unconscious motivated ignorance, which often involves self-deception. Because rationality here concerns the individual's own objectives, when motivated ignorance of any kind is irrational it typically harms the individual. For the remainder of this paper, however, I want to focus on a different phenomenon: cases in which rational motivated ignorance is harmful to others. Specifically, I will focus on the form of ignorance with which I began this paper: voter ignorance in contemporary democracies.

\section{Rational motivated voter ignorance}

One of the most socially consequential forms of ignorance today is the ignorance among voters in contemporary democracies of facts and matters of scientific consensus that are relevant to political decision-making. Of course, persistent public disagreement on many political issues is both predictable and desirable, insofar as such disagreement reflects differences in values and the large amount of uncertainty surrounding complex political decisions. However, there is now extensive data revealing extremely high levels of ignorance of basic matters of empirical fact around which there is strong scientific and expert consensus (Brennan 2016; Kahan et al. 2010; Somin 2013). In both political philosophy and political science, it is widely recognised that such persistent ignorance poses a deep challenge to democracy, 
which plausibly requires an informed electorate (Brennan 2016; Somin 2013). ${ }^{10}$ To take only one example-albeit an especially distressing one-many individuals are ignorant of the role of human activity in climate change and the various risks that it poses (Campbell and Kay 2014; Kahan et al. 2010). Indeed, when it comes to societal risks in general, the core explanandum for both psychology and social science is simple: "Why do members of the public disagree—sharply and persistently—about facts on which expert scientists largely agree?" (Kahan et al. 2010, p. 147).

There is clearly no single factor at play when it comes to explaining voter ignorance. Levels of ignorance are themselves highly variable among the population and also highly content-specific (Brennan 2016). Nevertheless, as I noted in Sect. 1, one influential explanation of voter ignorance points to rational acquisitional ignorance (Downs 1957; Somin 2013). According to this explanation, an individual voter has almost no practical incentive to acquire knowledge of the issues that she votes on because her vote has such a negligible impact on political decision-making. ${ }^{11}$ Given this, the costs of becoming informed greatly exceed the benefits of being informed. As Downs (1957, p. 259) puts it, "[T]he low returns from data simply do not justify their cost in time and other resources."

Although this explanation is surely applicable in many circumstances, it confronts several problems as a general account of voter ignorance. Perhaps most importantly, it fails to explain why voters are often systematically misinformed. ${ }^{12}$ That is, if the issue is merely that voters do not expend any time or energy in acquiring political knowledge, one would expect their errors to be randomly distributed around the truth. This is rarely the case, however (Caplan 2007; Flynn et al. 2017). Further, many of those holding misinformed opinions devote a large amount of time and energy to actively seeking out politically relevant information and engaging with the political process, and misinformed opinions are frequently held with high levels of confidence and emotional conviction-something that is difficult to understand in terms of acquisitional ignorance (Caplan 2001). Perhaps most mysteriously of all, those who diverge from expert consensus on many issues often appear to exhibit no worse understanding of the relevant issues than those who align with it (Kahan 2013, 2017a, b).

To account for such phenomena, I contend that we must turn to the costs that attend the possession of knowledge, and not merely its acquisition. That is, a significant component of voter ignorance is rational motivated ignorance: voters are responding to the costs of being informed, and not merely the costs of becoming informed. ${ }^{13}$ This fact is often hidden from view, however, because the motivated

\footnotetext{
${ }^{10}$ Exactly how and to what extent widespread ignorance challenges democracy is a difficult question within normative democratic theory (see Estlund 2005) that falls beyond the scope of the current paper.

${ }^{11}$ One explanation for why many voters are not ignorant is therefore that they assign non-instrumental value to political knowledge (Brennan 2016, p. 36).

${ }^{12}$ Although political scientists draw a distinction between ignorance and misinformation, being misinformed is of course a kind of ignorance (Flynn et al. 2017).

${ }^{13}$ See Caplan $(2001,2007)$, who emphasises the importance of "rational irrationality" (that is, epistemic irrationality that is instrumentally rational) in voter ignorance, although his emphasis is largely on the personal benefits that attend misguided beliefs rather than the costs that attend knowledge as such.
} 
ignorance central to the political domain is typically unconscious motivated ignorance. Nevertheless, knowledge in the political domain often brings costs, and there are compelling reasons to think that individuals respond to such costs. As with religious and ideological communities more generally, dissent from group dogmas and sacred propositions can issue in harmful forms of group ostracism, even when such heresies are best supported by the available evidence. Further, it is often painful to abandon deeply held political opinions and commitments, even when such abandonment is best licensed by an impartial evaluation of the facts. Drawing attention to such costs can help to explain how individuals exposed to a deluge of political information can remain both misinformed and yet passionately committed to such misinformation, and why understanding of politically relevant issues is often no guarantee of knowledge.

For example, consider the pioneering research carried out by Dan Kahan and colleagues on the causes of public ignorance of matters of societal risk such as climate change. As noted, the intuitive and widely held prediction that those who diverge from expert opinion in this area exhibit a worse understanding of the relevant scientific issues appears to be false (Kahan 2017a). ${ }^{14}$ Indeed, there is little or no positive correlation between people's generic scientific literacy and numeracy and the degree to which they align with scientific consensus on these topics. Further, those who score highest on so-called "cognitive reflection tests" that measure the degree to which one can override intuitive judgements and engage in careful deliberative reasoning are most polarized on issues such as climate change, which undermines the idea that ignorance in this domain is caused by cost-effective but biased "heuristics" or "System 1" thinking (Kahan 2017a). Instead, the one important thing that reliably correlates with ignorance concerning such issues is political identity (Kahan 2013, 2017a, b; Kahan et al. 2010).

Given this data, Kahan (2017a) speculates that issues such as climate change motivate individuals to engage in identity protective cognition, conforming the way in which they seek out and process information to the goal of protecting their political-coalitional identity rather than arriving at the truth. Specifically, because the positions that people take on climate change and related issues have become badges of coalitional affiliation and loyalty, individuals are incentivised "to attend to information in a manner that promotes beliefs that signal their commitment to the position associated with their group" (Kahan 2017a, p. 1). Although Kahan does not frame it in this way, this leads directly to a form of socially motivated ignorance. That is, identity protective cognition drives individuals who inhabit ideological communities where scepticism about climate change has become a badge of group identification to avoid acquiring any knowledge that might lead to exclusion or ostracism - that might lead them to lose this badge. Such knowledge avoidance can be sustained in various ways, including downgrading the epistemic authority of agents who assert identity-inconsistent views, using reasoning to

\footnotetext{
${ }^{14}$ However, see (Ranney and Clark 2016), who show that giving individuals particular kinds of climatespecific mechanistic and statistical information does seem to increase acceptance of the existence of climate change across the political spectrum, at least temporarily.
} 
find creative rationalisations for cherished beliefs, and the simple physical avoidance of identity-inconsistent information (Kahan 2017a). Indeed, evidence suggests that political partisans will pay to avoid exposure to contrary viewpoints and arguments (Frimer et al. 2017), which lends strong support to the motivated character of such information sampling.

Importantly, the socially motivated ignorance here can be of at least two kinds. For some, it is clearly a consequence of the motivation to possess-and so advertise-certain beliefs because they are socially rewarded (Williams 2019). This corresponds most closely to Brennan's (2016) metaphor of political "hooligans," in contrast to political "hobbits" whose ignorance is largely driven by rational acquisitional ignorance. In addition, however, there are surely partisans of different political parties whose primary interest is more in avoiding their side's condemnation than in performances that express their group allegiances. Extensive evidence in political science suggests that political outlooks are highly conditioned by social and political identity (Achen and Bartels 2017), but, at the psychological level, at least, there are important differences between showing off and fitting in, between hooliganism and motivated conformity, and between actively signalling one's loyalty and avoiding any cue of disloyalty.

Once again, there is no suggestion in either case that individuals are consciously aware of the role that their motives play in sustaining their ignorance in this domain. Indeed, most would vehemently reject this interpretation of their epistemic situation. In this sense the motivated ignorance that results from valued group identities and fear of group ostracism is typically-perhaps alwaysunconscious. From the individual's conscious point of view, it simply appears that all of the available evidence lends support to her opinions. As with paradigmatic forms of motivated reasoning, the fact that the individual's motivations played a central role in selecting and interpreting that evidence is hidden from view. Indeed, as suggested briefly above, the unconscious character of such motivations might itself be strategic, providing plausible deniability of the individual's irrationality. Crucially, however, this unconscious motivated ignorance is still plausibly instrumentally rational. When it comes to issues such as climate change, individuals have little practical incentive to hold true beliefs because as individuals they have a negligible impact on both the climate and political decision-making concerning the climate. That is, the potential benefits of knowledge are miniscule, even if one is altruistic. By contrast, forming true beliefs can be extremely costly if such beliefs happen to constitute heresies in the ideological community that one inhabits and values. As Kahan (2017a, p. 4) puts it,

Nothing an ordinary member of the public does as consumer, as voter, or participant in public discourse will have any effect on the risk that climate change poses to her or anyone else. Same for gun control, fracking, and nuclear waste disposal... But given what positions on these issues signify about the sort of person she is, adopting a mistaken stance on one of these in her everyday interactions with other ordinary people could expose her to devastating consequences, both material and psychic. 
Of course, although this phenomenon is individually (instrumentally) rational, it is socially catastrophic: if a large number of people in a democracy conform the way in which they seek out, ignore and process information to the goal of protecting their coalitional identity rather than achieving knowledge, the resultant ignorance will then likely play an important role in political decision-making. Further, as Kahan's quote illustrates, this basic phenomenon applies to many more cases beyond climate change. In fact, the basic dynamic will apply whenever the acquisition of knowledge is heretical and thus socially punished on the grounds that unjustified beliefs function as signals of coalitional membership and belonging. Given what we know about the history of politically relevant coalitions (religions, economic classes, political parties, ethnic groups, etc.), this situation is plausibly pervasive.

Kahan's research does raise an important question, however: how do unfounded beliefs about matters of empirical fact become signals of coalitional membership and loyalty to begin with? Once again, there is surely no single factor that explains the emergence of such associations. For example, one distressing suggestion in this area is that beliefs that perform such signalling functions are inherently biased towards implausibility, both because out-group members have no evidential reason to hold such beliefs and because the reputational damage associated with believing absurdities generates a costlier — and so more reliable - signal of coalitional loyalty (Simler and Hanson 2017; Tooby 2017). A distinct causal pathway that plausibly plays an important role in the political domain, however, is the phenomenon of solution aversion, the process by which one denies the existence of a problem because one dislikes its available solutions (Campbell and Kay 2014).

Consider climate change again. It is widely held that solving the problems created by anthropogenic climate change requires various kinds of market regulation and thus government intervention. Given this, those who are invested in a political ideology that condemns extensive governmental interference in the economy acquire a motivation to deny that the relevant problem exists. As a result, denial of the problem becomes an entrenched position among those who hold the relevant ideology. And-again - this is not restricted to climate change, and it is an issue that can arise in any ideology. Just as an alcoholic might be in denial about the extent of her alcohol problem because she is averse to the obvious solution to this problem (Pickard 2016, p. 290), ideologies that condemn certain kinds of actions can motivate denial of any problems that would require such actions as solutions. Further, such denial is perfectly instrumentally rational from the ideologue's point of view: if one has little practical incentive to hold true beliefs, the benefits of indulging one's ideological prejudices can overcome the negligible personal costs of ignorance. As Caplan (2007, p. 18) puts it, "In real-world political settings, the price of ideological loyalty is essentially zero."

As these examples illustrate, then, focusing on rational motivated ignorance helps to illuminate such phenomena. That is, in many of these cases individuals appear to be responding to the costs of knowledge itself, rather than to the costs of acquiring knowledge - and, moreover, they are doing so in a way that is perfectly (practically) rational. Nevertheless, such individual rationality is socially catastrophic: whilst the individual costs of individual ignorance might be vanishingly small, the social costs of collective ignorance are enormous. 
Of course, this topic warrants substantially more research in the future, both analytical and empirical. For example, in some cases it is clear that powerful individuals and institutions have a more direct interest in denialism (for example, oil companies in the case of climate change), and they likely also play an important role in deliberately fostering associations between certain coalitions and unjustified beliefs (Levy 2019). Further, some forms of denial in the political sphere are plausibly not tied to coalitional identity or political ideology at all but rather reflect a more general human tendency to avoid recognising problems that generate anxiety (Marshall 2014, p. 228).

More generally, future work should expand upon and scrutinise two major aspects of the foregoing analysis. First, although I have focused on identity and ideological investment as core motivations for ignorance among voters, these clearly do not exhaust the complex motivations in this area. Future research would thus benefit from a more exhaustive analysis of the motivational drivers of politically relevant ignorance. Second, although I have followed thinkers such as Caplan (2007) and Kahan $(2013$, 2017a) in arguing that non-epistemic motivations play a significant role in sustaining voter ignorance, there are competing explanations of at least some of the phenomena identified in this section. For example, alternative explanations of the correlations between political identity and ignorance point to things such as the different informational environments that people inhabit, and their general dependence on complex chains of testimony in which in-group membership is often used as a guide to trustworthiness (Levy 2019). Although adjudicating between such competing explanations is a live area of research in the social sciences (Lelkes et al. 2018), future work that attempts to ground voter ignorance in motivated ignorance in the manner that I have done here must deal more extensively with competing accounts of this complex phenomenon.

Finally, it should be obvious that the phenomena described in this section by no means exhaust the ways in which rational motivated ignorance can be collectively harmful. For example, I have already noted the work of feminist philosophers and critical philosophers of race who have drawn attention to the way in which members of elite and powerful demographic groups wilfully avoid—and, more generally, benefit from ignorance of - aspects of the lives of oppressed groups in society (see, e.g., Mills 2007), and Moody-Adams (1999, p. 180) argues that "the main obstacle to moral progress in social practices" in general "is the tendency to widespread affected ignorance of what can and should already be known." Thus, although my focus has been on simple kinds of voter ignorance, studying the way in which rational motivated ignorance can have socially harmful—even catastrophic-effects is a much broader topic. I hope that the present work will contribute to the analytic foundations of this project and future research within it.

\section{Conclusion}

In this paper I have sought to clarify a pervasive and important phenomenon: cases in which individuals remain ignorant not because of a lack of available information, and not because of the various costs associated with acquiring that information, 
but because of the costs associated with knowledge itself. I have sought to illuminate the circumstances in which this phenomenon is instrumentally rational, and I have argued that rational motivated ignorance plays a large but often underappreciated role in one of the most pernicious and socially consequential forms of ignorance today: ignorance among voters in contemporary democracies. As I have noted throughout, this paper leaves many important questions unanswered. Nevertheless, I hope that it has drawn attention to a set of issues that warrant more attention in philosophy and that it has taken some important steps in addressing them. To conclude, I want to flag two important implications of the paper.

First, and most obviously, the phenomenon of ignorance cannot be understood through a purely epistemological lens. We are not impartial seekers of knowledge, even if it often seems that way to us. We are social animals whose orientation to knowledge is fundamentally strategic. Knowledge is risky. It threatens our comforting illusions, undermines our wishful thinking, drives us towards undesirable actions and destabilises the social relationships that we depend upon for meaning and belonging. Insofar as motivated ignorance is a significant feature of human life, then, ignorance in general cannot be understood without focusing on a variety of highly practical considerations: the contingencies of our circumstances and motivations, and the structure of the social worlds that we inhabit. Of course, this is a central lesson of the work on ignorance by feminist philosophers and critical philosophers of race (Frye 1983; Mills 2007; Woomer 2019). I hope that the current paper reinforces it.

Second, and relatedly, the foregoing considerations suggest powerful lessons for how to address ignorance. An intuitive view is that the answer to socially pernicious forms of ignorance is to provide people with more information, perhaps combined with an appeal to their reason. This is unlikely to help when ignorance is motivated. Such ignorance is not caused by a lack of available information, and in many cases the problem is precisely that individuals are treating potential knowledge in a way that is rational. Instead, one has to address the root of the problem: the practical considerations that make knowledge costly for individuals. In cases in which ungrounded beliefs are signals of coalitional identity, for example, the task must consist of attempting to depoliticise such issues - to show that one can maintain one's membership in a desirable coalition without renouncing a commitment to knowledge, perhaps by encouraging influential in-group members to adopt a dissenting view (Nyhan 2013). Similarly, insofar as solution aversion is an important cause of denial in the political domain, it suggests that public information campaigns should work hard to decouple the recognition of problems from a specification of available solutions (see, e.g., Kahan et al. 2012). More generally, solving the problems associated with motivated ignorance requires a far more complex and demanding set of individual and collective strategies - strategies that can only be identified, let alone executed, with a proper understanding of the practical incentives that people have for burying their heads in the sand.

Acknowledgements This work was generously supported by the Fonds voor Wetenschappelijk Onderzoek (FWO) Odysseus grant [G.0020.12 N] and the Fonds voor Wetenschappelijk Onderzoek (FWO) research grant [G0C7416N] and by a Research Fellowship from Corpus Christi College, University of 
Cambridge. I would like to thank Bence Nanay for helpful comments and suggestions on an early version of the manuscript, and several members of the Centre for Philosophical Psychology at the University of Antwerp more broadly for helpful feedback: Kevin Lande, Nick Wiltsher, Gerardo Viera, Alma Barner, and Magdalini Koukou. I would also like to thank the 4 (!) anonymous reviewers for helpful criticisms and suggestions throughout the review process.

Open Access This article is licensed under a Creative Commons Attribution 4.0 International License, which permits use, sharing, adaptation, distribution and reproduction in any medium or format, as long as you give appropriate credit to the original author(s) and the source, provide a link to the Creative Commons licence, and indicate if changes were made. The images or other third party material in this article are included in the article's Creative Commons licence, unless indicated otherwise in a credit line to the material. If material is not included in the article's Creative Commons licence and your intended use is not permitted by statutory regulation or exceeds the permitted use, you will need to obtain permission directly from the copyright holder. To view a copy of this licence, visit http://creativecommons.org/licen ses/by/4.0/.

\section{References}

Achen, C. H., \& Bartels, L. M. (2017). Democracy for realists: Why elections do not produce responsive government. Oxford: Princeton University Press.

Adams, D. (1980). The Restaurant at the end of the universe. London: Pan Books.

Anonymous, Alcoholics. (2001). Alcoholics anonymous (4th ed.). New York: Alcoholics Anonymous World Services Inc.

Bankier, D. (1996). The Germans and the final solution: Public opinion under Nazism. London: Wiley-Blackwell.

Bénabou, R., \& Tirole, J. (2016). Mindful economics: The production, consumption, and value of beliefs. Journal of Economic Perspectives, 30(3), 141-164. https://doi.org/10.1257/jep.30.3.141.

Bortolotti, L. (2014). Irrationality. Cambridge: Wiley.

Brennan, J. (2016). Against democracy. Oxford: Princeton University Press.

Campbell, T., \& Kay, A. (2014). Solution aversion: On the relation between ideology and motivated disbelief. Journal of Personality and Social Psychology, 107(5), 809-824. https://doi.org/10.1037/ a0037963.

Caplan, B. (2001). Rational ignorance versus rational irrationality. Kyklos, 54(1), 3-26. https://doi. org/10.1111/1467-6435.00138.

Caplan, B. (2007). The myth of the rational voter: Why democracies choose bad policies. Princeton: Princeton University Press.

Carruthers, P. (2015). The centered mind. Oxford: Oxford University Press.

Downs, A. (1957). An economic theory of democracy. New York: Harper \& Row.

Estlund, D. (2005). Democratic theory. In F. Jackson \& M. Smith (Eds.), Oxford handbook of contemporary philosophy (pp. 208-230). Oxford: Oxford University Press.

Flynn, D., Nyhan, B., \& Reifler, J. (2017). The nature and origins of misperceptions: Understanding false and unsupported beliefs about politics. Political Psychology, 38, 127-150. https://doi.org/10.1111/ pops. 12394.

Fricker, M. (2016). Epistemic injustice and the preservation of ignorance. In R. Peels \& M. Blaauw (Eds.), The epistemic dimensions of ignorance (pp. 144-159). Cambridge: Cambridge University Press.

Frimer, J. A., Skitka, L. J., \& Motyl, M. (2017). Liberals and conservatives are similarly motivated to avoid exposure to one another's opinions. Journal of Experimental Social Psychology, 72, 1-12.

Frye, M. (1983). The politics of reality: Essays in feminist theory. Freedom, CA: Crossing Press.

Funkhouser, E. (2017). Beliefs as signals: A new function for belief. Philosophical Psychology, 30(6), 809-831. https://doi.org/10.1080/09515089.2017.1291929.

Funkhouser, E. (2019). Self-deception. London: Routledge.

Golman, R., Hagmann, D., \& Loewenstein, G. (2017). Information avoidance. Journal of Economic Literature, 55(1), 96-135. 
Hertwig, R., \& Engel, C. (2016). Homo Ignorans. Perspectives on Psychological Science, 11(3), 359372. https://doi.org/10.1177/1745691616635594.

Holton, R. (2001). What is the role of the self in self-deception? Proceedings of the Aristotelian Society, 101(1), 53-69.

Kahan, D. (2013). Ideology, motivated reasoning, and cognitive reflection. Judgment and Decision Making, 8, 407-424.

Kahan, D. (2017a). The expressive rationality of inaccurate perceptions. Behavioral and Brain Sciences, 40, 26-28. https://doi.org/10.1017/s0140525x15002332.

Kahan, D. (2017b). Misconceptions, misinformation, and the logic of identity-protective cognition. SSRN Electronic Journal. https://doi.org/10.2139/ssrn.2973067.

Kahan, D., Jenkins-Smith, H., \& Braman, D. (2010). Cultural cognition of scientific consensus. SSRN Electronic Journal. https://doi.org/10.2139/ssrn.1549444.

Kahan, D. M., Jenkins-Smith, H., Tarantola, T., Silva, C. L., \& Braman, D. (2012). "Geoengineering and climate change polarization: Testing a two-channel model of science communication. Annals of the American Academy of Political and Social Science, 658, 193-222.

Kahneman, D. (2003). Maps of bounded rationality: Psychology for behavioral economics. American Economic Review, 93(5), 1449-1475.

Kunda, Z. (1990). The case for motivated reasoning. Psychological Bulletin, 108(3), 480-498.

Kurzban, R. (2012). Why everyone (else) is a hypocrite. London: Princeton University Press.

Lelkes, Y., Malka, A., \& Bakker, B. N. (2018). An expressive utility account of partisan cue receptivity: Cognitive resources in the service of identity expression. Unpublished manuscript, Annenberg School for Communication, University of Pennsylvania. Retrieved from https://pdfs.semanticscholar .org/dc57/456399c71dfb8ed13bc52bb65c0857987a0f.pdf.

Levy, N. (2019). Due deference to denialism: Explaining ordinary people's rejection of established scientific findings. Synthese, 196(1), 313-327. https://doi.org/10.1007/s11229-017-1477-x.

Locke, J. [1689](1976). An essay concerning human understanding. In S. Cahn (Ed.), Classics of western philosophy. Indianapolis: Hackett Publishing Company.

Lynch, K. (2016). Willful ignorance and self-deception. Philosophical Studies, 173(2), 505-523.

Marshall, G. (2014). Don't even think about it: Why our brains are wired to ignore climate change. New York, London: Bloomsbury.

Mele, A. (2001). Self-deception unmasked. Princeton, NJ: Princeton University Press.

Mills, C. (2007). White ignorance. In Race and epistemologies of ignorance. Albany: State University of New York Press.

Moody-Adams, M. M. (1999). The idea of moral progress. Metaphilosophy, 30, 168-185.

Nelkin, Dana. (2002). Self-deception, motivation, and the desire to believe. Pacific Philosophical Quarterly, 83(4), 384-406.

Nyhan, B. (2013). Building a better correction. Columbia Journalism Review. http://archives.cjr.org/unite _states_project/building_a_better_correction_nyhan_new_misperception_research.php.

Oster, E., Shoulson, I., \& Dorsey, E. R. (2013). Optimal expectations and limited medical testing: Evidence from Huntington disease. American Economic Review, 103(2), 804-830.

Pickard, H. (2016). Denial in addiction. Mind and Language, 31(3), 277-299. https://doi.org/10.1111/ mila.12106.

Ranney, M. A., \& Clark, D. (2016). Climate change conceptual change: Scientific information can transform attitudes. Topics in Cognitive Science, 8(1), 49-75.

Ross, W. D. (Ed.). (1924). Aristotle's metaphysics. Oxford: Clarendon Press.

Schelling, T. (1960). The strategy of conflict. Cambridge, MA: Harvard University Press.

Simler, K., \& Hanson, R. (2017). The elephant in the brain. Oxford: Oxford University Press.

Simon, W. H. (2004). Wrongs of ignorance and ambiguity: Lawyer responsibility for collective misconduct. Columbia Public Law \& Legal Theory Working Paper, No. 0480.

Somin, I. (2013). Democracy and political ignorance: Why smaller government is smarter. Stanford: Stanford University Press.

Somin, I. (2015). Rational ignorance. In L. J. McGoey \& M. Gross (Eds.), Routledge international handbook of ignorance studies. London: Routledge.

Stanovich, K. (2011). Rationality and the reflective mind. Oxford: Oxford University Press.

Stigler, G. (1961). The economics of information. Journal of Political Economy, 69(3), 213-225. https:// doi.org/10.1086/258464.

Sweeny, K., Melnyk, D., Miller, W., \& Shepperd, J. (2010). Information avoidance: Who, what, when, and why. Review of General Psychology, 14(4), 340-353. https://doi.org/10.1037/a0021288. 
Thagard, P. (2013). Motivated ignorance. Psychology Today. https://www.psychologytoday.com/intl/ blog/hot-thought/201301/motivated-ignorance. Accessed 28 May 2019.

Tooby, J. (2017). Coalitional instincts. Edge. https://www.edge.org/response-detail/27168.

von Hippel, W., \& Trivers, R. (2011). The evolution and psychology of self-deception. Behavioral and Brain Sciences, 34(01), 1-16.

Wieland, J. (2016a). Responsibility for strategic ignorance. Synthese, 194(11), 4477-4497. https://doi. org/10.1007/s11229-016-1145-6.

Wieland, J. (2016b). Willful ignorance. Ethical Theory And Moral Practice, 20(1), 105-119. https://doi. org/10.1007/s10677-016-9722-9.

Williams, D. (2018). Hierarchical Bayesian models of delusion. Consciousness and Cognition, 61, $129-147$.

Williams, D. (2019). Socially adaptive belief. Mind and Language.

Woomer, L. (2019). Agential insensitivity and socially supported ignorance. Episteme, 16(1), 73-91.

Publisher's Note Springer Nature remains neutral with regard to jurisdictional claims in published maps and institutional affiliations. 